\title{
Unusual Carbonatite Lavas from Active Volcano, Oldoinyo Lengai
}

A letter appearing in Nature (7 May 2009) explains the unusual extrusion of carbonatite lavas (containing more than 50\% carbonate minerals) at Oldoinyo Lengai gorge in Tanzania to the possible existence of magma reservoirs formed in the shallow crust by immiscibility from silicate magmas which are stable under eruption conditions due to their high sodium contents (p.5 and p.77) $-B P R$ 